\title{
Transformation Capability And Employee Performance In Selected Aluminium Manu Facturing Firms In Anambra State
}

\author{
Ebolum Ikechukwu Charles, Ojukwu Henry Sonna, Azotani Francis Chuks \\ (Department of Business Administration /Nnamdi Azikiwe University, Awka, Nigeria) \\ (Department of Business Administration /Nnamdi Azikiwe University, Awka, Nigeria) \\ (Department of Business Administration /Chukwuemeka Ouimegwu Ojukwu University, Nigeria)
}

\begin{abstract}
The objective of this study was to determine the type of relationship existing between Transformational Capability and Employees Performance of selected aluminium manufacturing companies in Anambra State. The study was anchored on the Theory of Structural Empowerment. The study employed a correlation research design. The population of the study was 132 consisting of employees of the three selected companies used in the study, the sample size was 123 which was arrived at using Taro Yamani Formula. Pearson's Product Moment Correlation Co-efficient which seeks to establish the relationship between the dependent and independent variable was used in analysing the data. The findings revealed that Autonomy in Decision making has a significant positive relationship with Employee Commitment; hence the researcher recommended among other things that Management should empower the employees with autonomy to make decisions as this will have a positive effect on their commitment level.
\end{abstract}

Keywords: Autonomy in decision making, employee performance, employee commitment and Transformation capability.

\subsection{Background of the study}

\section{Introduction}

Organizations exist in a highly dynamic and volatile environment where what is obtainable today fizzles out within a twinkle of an eye, and so organizations take the art of changing and transformation as a very serious business. They (the organizations) are always in stiff competition; they are always mapping out plans and strategies on how to distinguish themselves from others in other to gather greater market share, more customers and retain their loyalty, retain the assets they have in the form of experienced workers and retain their commitment. To achieve these seeming lofty goals and ambitions, organizations keeps changing and transforming from a particular stage and state of activities to a greater stage and state of activity in other to distinguish its self from others. The question of what distinguishes successful companies from companies that are not successful is as old as management research itself. The reason for such performance differences play an important role in the survival of a company, the performance of a company within a certain industry is commonly attributed to certain distinctive capabilities or competencies where transformation capability seem to be top on the list of capabilities needed to continue being relevant in the industry. The capabilities of these organizations to transform and change is however another issue all together as some organizations seem to be very good at transforming and progressing, others seem to have stagnated while others still seem to be retrogressing.

The transformational capabilities of organizations depend on how innovative they are In terms of ideas generated either through internal source (in-house employees) or external source (experts and consultants). This is probably the reason organizations value innovative ideas, ideas that will help transform the organization from a modest firm to a blue-chip firm that will be reckoned with in the industries and so from time to time, organizations come up with various innovative ideas that could change the production process of the organization or improve its value chain and supply capabilities in other to serve its customers well. That is why almost on a daily basis, the manufacturing industry is come up with new products in new packages and with new uses. The impact of these transformational ideas on the organization is always holistic, same could also be said of its effects on the performance of the employees. However, some of the transformational ideas come at a cost to the organization and to the employees as well. The employees sometimes have to relinquish some of their powers to accommodate the transformation and change going on the organization while some are asked to change offices and positions in the organization. It was observed in the focused firms that some of the transformational ideas introduced by the organization reduces the decision making power of the employees, they seem to have to report to a higher authority before making decisions they were able to make before the transformation took place. Some of the transformational ideas create wider span of control and longer hierarchy of authorities and responsibilities thereby eroding some employees of their hitherto decision making powers and authorities. This actions and new development could have negative impacts on the performance of the 
employees. A once happy employees may as a result of transformation introduced in the organization start to rethink certain issues like how committed they will be, whether it is worthwhile to continue offering their services to the organization or whether they should look elsewhere where they will have their vibes and happiness back. The implication of the decision of the employees about these issues plays a major role in determining the performance of the organization because when employees reduce their commitment level and withdraw their services from an organization, the effect could be disastrous to the very existence of the organization.

\subsection{Statement of the Problem}

Organizations always strive to transform their activities in other to remain relevant in the industry. They could transform along the line of production process, value chain, diversification and market penetration. All these changes most times require some kind of restructuring of the organization structure. As a result of this redesign, some employees may be given higher authorities and responsibilities while others may have to relinquish their authorities and decision making powers. It was observed in the focused organization that some of the innovative and ingenious ideas that help the organizations to transform and move ahead of their competitors reduces the decision making power of some of the employees. Some of the employees who hitherto had the powers to take certain decision without having to consult with a higher authority as a result of the changes in the structure of the organization to accommodate the transformation in the organization now have to wait for higher authorities to take such decisions. This acts delays processes and procedures and may affect the response time of the organization. The result of such redesign of the organization structure could also be felt in the performance of the employees. A once committed employee as a result of decision making autonomy may find such commitment and job satisfaction eroding him because his locus of control is now external. This may significantly affect the performance of the organization as a whole because an uncommitted employee may decide to withdraw his services and offer same services to a competitor who will use their knowledge and experience of their old firm against them. It is as a result of this that the researcher found it necessary to examine the type of relationship existing between transformation capability and employee performance.

\subsection{Objectives of the Study}

The broad objective of the study is to explore the type of relationship existing between Transformation Capability and Employee Performance of the selected Aluminium Manufacturing Companies in Anambra State. However, the specific objective is:

1. To ascertain the type of relationship existing between Autonomy in Decision Making and Employee commitment of the focused organizations.

\subsection{Research Question}

What is the type of relationship existing between Autonomy in Decision Making and Employee Commitment of the focused organizations?

\subsection{Research Hypothesis}

$\mathrm{H}_{\mathrm{A}}$ : There is a significant positive type of relationship existing between Autonomy in Decision Making and Employee Commitment of the focused organizations.

\subsection{Significance of the Study}

The findings of the study will be useful to researchers, consultants and many organizations especially aluminium companies in Anambra State and Nigeria in General that seek to outshine competitors by making them abreast with the problem identified. They will as a result of this study, empower employees to think independently which will have a multiplier effect on the company's overall performance.

1.7 Scope of the study

The study examines transformation capability and employee performance in selected aluminium manufacturing companies in Anambra State. The companies selected for the study are Flight Aluminum Nig Ltd in Onitsha, Map Aluminium\& Steal Ind Ltd in Nnewi and Arcmaster Aluminum Products

1.8 Limitation of the Study

The researcher encountered difficulty in retrieving some of the questionnaire, also, the sampling technique used is a non-probability sampling and hence involves some atom of biasness. Some of the respondents also were difficult to convince as to the reason of the questionnaire, it took painstaking effort to make them realize that it was merely for academic purpose

\section{Review Of Related Literature}

\subsection{Conceptual Review}

\subsubsection{Transformation Capability}

Research on organizational capabilities started during the 1990s and was anchored on the resource based view (Wemer, 1984). The notion of capability has been defined as a capacity for a team of resources to 
perform some task or activity. Amit and Schoemaker (2012) suggested that capability refers to a firm's capacity to deploy resources, usually in combination using organizational processes, to effect a desired end. They are information-based tangible or intangible processes that are firm-specific and are developed over time through complex interaction among the firms resources. For these authors, the notion of capability involves thus- a performance target, a resources combination, organizational processes and development over time. First, organizational capabilities are considered as a major source for the generation and development of sustainable competitive advantage (Baney, 2012). In strategic management literature, capabilities are depicted as critical success factors. Secondly, organizational capabilities are linked to a combination of resources. Miller (2003) defined capability as a bundle of complementary resources. Although the possession of resources is a binary issue, the ownership of a capability is a matter of degree. Third, organizational capabilities are based upon organizational processes and routines. Lastly, organizational capabilities results from a development over time. Transformation capability has been viewed and analysed by different researchers. Bechky (2013) posit that organizational transformational capability can be defined as the ability to sense the need to align resources, culture, process and technology to achieve new forms of competitiveness. The notion of organizational transformation capability is derived from dynamic capability paradigm. Dynamic capability can be defined as the firm's ability to integrate, build and reconfigure internal and external competence to address a rapidly changing environment (Teece, Pisano \&Shuen, 2013). It requires the capability to extract economic benefits from the current resources and develop new capabilities. According to Zhan and Lou (2014), a firms transformation capability enhances its competitive advantage and its seen as resting distinctive processes (ways of coordinating and combining) shaped by the firms specific asset positions such as the firms portfolio of difficult- to- trade knowledge assets and complimentary assets and evolution paths it has adopted or inherited. It emphasizes the capability to combine, coordinate and configure the resources and assets base of an organization. Lado, Boyd and Wright (2012) emphasizes transformation based competence as one of the four components of firms distinctive competences which may be conceived as those organizational capabilities required to advantageously convert inputs into output. In the reconfiguration view, firm level innovation rest on the ability to realizing new combination of firms resources. According to him, a product development is a dynamic capability of the firm because of its ability to alter the resources configuration of the firm. Product development is one of the mechanisms by which firms create, integrate, and combine resources.

Galunic and Rodan (2014) argued that transformation based competence as one of the four components distinctive competences which may be conceived as those organizational capabilities required to convert inputs into outputs. In the reconfiguration view, firm-level innovation rests on the ability to realize new combination of firms resources while capability is referred to as a firm's capacity to deploy resources usually in combination and encapsulate both explicit processes and those tacit element such as know-how and Leadership embedded in the process. Hence capabilities are often firm- specific and are developed over time through complex interaction among the firm's resources (Amit \&Schoemaker, 2003). For example quality control is a process that can be easily adopted by firms, whereas total quality management is not just a process but requires the firms' capability of developing an organization wide vision, empowering employees and building a customer orientation culture. Wang and Ahmed (2008) posits that transformation capability is a firm's ability to develop new products and or markets through aligning strategic innovative orientation with innovative behaviour and processes. As indicated in the definition, transformative capability encompasses several dimensions. Prior research has emphasize the different combination of this dimension for example Schumpeter (1934) as cited in Reichert (2013) suggested a range of possible innovative alternatives namely developing new products or services, developing new methods of production, identifying new markets, discovering new sources of supply and developing new organizational forms.

Miller and Friesen (1983) focused on four dimensions; new products or services, innovation methods of production or rendering of services, risk taking by key executives and seeking unusual and novel solutions. Whereas, the term innovation can be defined as something original and more effective in terms of device or process, it is the application of better solutions that meets new requirements, unarticulated needs or existing market needs. This is accomplished through more effective products, processes, services, technologies or ideas that are readily available to the market.

\subsubsection{Employee Performance}

Ayegh (2014) defined employee performance as a consistent ability to produce results over prolonged period of time. Employee performance is the consistent ability of an employee to execute their job roles and responsibility well enough. This is the job related activity expected of a worker and how well those activities were executed. Many business personnel directors assess the employee performance of each staff on an annual or quarterly basis in order to help identify suggested areas for improvement. Employee empowerment generally means the process of allowing employees to have input and control over their work and the ability to share suggestions and ideas about their work and the organization as a whole. Empowered employees are committed, 
loyal and conscientious; they are eager to share ideas and can serve as strong ambassador for their organization. Followers are empowered to think on their own, develop fresh ideas and question operating rules that are obsolete. Employees whom are empowered through the company's innovative ideas are expected to perform better and remain committed to the firm which will have a multiplier effect on the company innovativeness. This is a management practice of sharing information, rewards, and power with employees so that they can take initiative and make decisions to solve problems and improve services and performance. Employee empowerment is based on the idea that giving employees skills, resources, authority, opportunities and motivation as well as holding them responsible and accountable for outcomes of their actions, will contribute to their competence and satisfaction.

\subsubsection{Decision Autonomy}

Decision Autonomy is the degree or level of freedom and discretion allowed to an employee over the decision concerning his job and role (Hackman \& Oldham, 1976). Autonomy is the degree to which a person has the freedom to decide how to perform his or her tasks. Autonomy plays an important role in determining the motivation level of employees and their innovativeness. If you give an employee discretion to make decisions and come up with new ideas, such an employee will be motivated. This was captured by Petrova (2011) when he said if we accept that workers are either motivated or unmotivated, offering autonomous jobs to unmotivated workers will stimulate them to be more motivated. Autonomy increases motivation at work, but it also has other benefits. Giving employees' autonomy at work is a key to individual as well as company success, because autonomous employees are free to choose how to do their jobs and therefore can be more effective. Giving employees autonomy is also a great way to train them on the job. Job with high degree of autonomy creates a sense of responsibility and greater job satisfaction in the employee (Chu, 2006). Higher level employees were more satisfied because they enjoyed more opportunity to satisfy their ego needs, high status, higher payment and self - direction than lower level employees (Sisodia\& Das, 2014). Decision autonomy can play an important role in enhancing the performance of the employee in the organizations; it will make them come up with new ideas that will change and transform the fortune of the organization for the better. It creates a sense of ownership and belonging in the employees. This was corroborated by Dean, Colarelli\&Konstans, (2007) when they said decision autonomy creates a sense of responsibility among the employees of the organization. They show an increasing impact of decision autonomy on the employee performance and the absence of decision autonomy in the organizations creates so many problems like decrease in productivity, performance, reduced innovativeness and idea generation and solution proffering capability and increase in stress (Zia-ur-Rehman\& Tariq, 2012)

\subsubsection{Employee Commitment}

Akintayo (2010) defined employee commitment as the degree to which the employee feels devoted to their organization. Ongori (2007) described employee commitment as an affective response to the whole organization and the degree of attachment or loyalty employees feel towards the organization. Zheng, (2010) describes employee commitment as simply employees' attitude to organization. The commitment level of the employees determines to what extent employees are willing to go for an organization. This assertion was made known by Dixit and Bhati (2012) when they said that employee commitment reflects the extent to which employee's identify with and organization and is committed to its goals. Organizational commitment or employee loyalty is the degree to which an employee identifies with the organization and wants to continue participating actively in it (Solomon, 1992). Biljana and Dordevic (2004) stated that the commitment of employees is an important issue because it may be used to predict employee's performance, absenteeism and other behaviors. Commitment is a force that binds an individual to a course of action of relevance to one or more targets (Meyer \&Herscovitch 2001). 'Binding' here refers to the maintenance of the relationship with the commitment object and is seen as the most important outcome of commitment (Meyer et al. 2002) According to the Meyer \& Allen (1997) commitment “is a psychological state that characterizes the employee's relationship with the organization and has implication for the decision to continue membership in the organization." The committed employee has been found to be more creative; they are less likely to leave an organization than those who are uncommitted.

Organizations value commitment among their employees because it is typically assumed to reduce withdrawal behaviour, such as lateness, absenteeism and turnover (Irefin\& Mechanic 2014). Lo (2009) noted that employees with sense of employee commitment are less likely to engage in withdrawal behaviour and more willing to accept change. Most organizations have realized that the performance of their workers plays a vital role in determining the success of the organization (Zheng, 2010; Ajila and Awonusi, 2004). One of the antecedent determinants of workers' performance is believed to be employee commitment (Ali, 2010; Ajila and Awonusi, 2004). 


\subsection{Theoretical Framework}

This work is anchored on the Theory of Structural Empowerment credited to the work of Kanter (1977). This theory states that the behaviour of employees with respect to idea generation and proffering solutions to burning issues in the organization depends on the level of empowerment given to them in terms of decision making and the usage of suggestions brought forward by the employees. Empowerment here according to this theory also means the level of opportunity given to the employees for growth and mobility, the amount of power possessed by employees to access resources and information to carry out their duties and the leeway to make decisions concerning their duties in the organization. This theory has it that when employees are provided with access to information, resources, support and the opportunity to learn and develop, freewill to make decisions, then it can be said that such an organization promotes empowerment of employees and such organization should expect nothing less than a committed workforce(Larkin, Ciepial, Stack, Morrison \& Griffith, 2008). The theory of Structural Empowerment was chosen for this work because the transformational ideas introduced by the focused firms eroded some of the employees their decision making power which is an expected of employee empowerment.

\subsection{Empirical Review}

Zhangwei, Hangzhou and Xiang (2015) carried out a study to investigate innovation culture, transformation capability and transformational performance of SMEs in China. The data was analyzed with the use of Pearson's product moment correlation. The study points out that innovation culture have remarkably positive effects on transformational performance. The study further indicated that transformational capabilities evidently mediates the impacts of innovation culture on transformational performance.

Albu (2012) examined the role of organizational transformation capability that affects strategic platform uniqueness, capable resource establishment and swirl innovative knowledge which link to firms sustained competitive advantage. With a sample size of 120 respondents the data was analyzed using $\mathrm{Z}$ test statistic, The result showed that the organizational transformation capability lead to preferences for greater strategic platform uniqueness capable resource establishment and swirl innovative knowledge that link to firm competitive advantage through the competency to align resources, culture, process and technology to achieve new forms of competitiveness. It also reviews that swirl innovative knowledge is not positively associated with firms sustained competitive advantage. The result is inconsistent with prior result and main logic of knowledge creation theory.

Cavazotte, Moreno and Bernardo (2013) examined transformational leaders and work performance. They equally proposed and tested two mediating processes through which transformational leaders will enhance the performance of their staff; stronger follower identification with the leader and efficacy beliefs. These relations were tested with a sample of 107 managers from a multinational company. The result suggested that perceived transformational leadership is associated with higher levels of task performance and helping behaviours. Grunbaum and Stenger (2014) examined transformation capabilities and profitability of Small and medium sized enterprises operating in volatile environment. Correlation analysis was used in analyzing the data. The findings revealed a positive relationship between transformation capabilities and innovation performance in the case enterprise. It was however not possible to establish neither a positive relationship between innovation performance and profitability nor any positive relationship between dynamic capability and profitability.

Chew and Lo (2008) studied core capabilities an competition strategies of Chinese small and medium-sized enterprises, and considered that core capabilities are closely related to competition strategies in which core capabilities included entrepreneurship, marketing and innovation capability; and potential competition strategies include cost, quality, distribution and cooperation.

Lynch,Grover and Lin (2000) used structural equation model to study the relationships among logistics capability, strategy and performance. The logistic capability combinations presented included added value services capability and process capability. The result shows that added value services and process capability are related to firms' performance and suggested that firms should invest in research and development to develop new capabilities in areas of value added services.Olajide (2014) examined change management and its effects on employee performance of Nigeria's telecom industry: Empirical insight from Airtel Nigeria, a total of 300 staff of Airtel were randomly selected from staff population of 1000, the result was analyzed with ANOVA and the result revealed that; changes in technology has a significant effect on performance and that changes and customer taste has a significant effect on customer patronage. The result also reveal that changes in management leadership has a significant effect on employee performance. Based on the findings recommendations were made that telecom industries in Nigeria should be proactive to changes in such a competitive environment so as to experience smooth implementation of such changes.

Oyejido (2012) examined strategic agility and competitive performance in the Nigeria telecommunication industry using a multiple informed survey, data on profits growths, sales revenue, financial strength, operating efficiency and performance stability were collected from the firms records. The result from 
the analysis showed a significant relationship between strategic agility and competitive performance. It was found that strategic agility influence competitive performance of telecommunication firms in Nigeria.

Akinbade (2014) examined transformation strategies and improved performance of selected Nigeria telecommunication companies. The findings revealed a positive relationship between transformation strategies and performance of telecommunication companies. It is recommended that universal mobile telecommunication services (UMTS) operators should adopt the culture of transformation strategies since it can impact on their performance for achieving competitive advantage.

\section{Summary of reviewed literature}

Zhangwei et al (2015) examined innovation culture, transformational capability and transformational performance of SMEs in China, the result showed that innovation culture have remarkably affected transformational performance. In a similar work of Albu, M (2012) on the role of organizational transformational capability that affect strategic platform uniqueness, capable resources establishment and swirl innovative knowledge. The result showed that the organizational transformation capability lead to preference of greater strategic platform uniqueness etc. in another study by Oyejido (2012) on strategy agility and competitive performance in Nigeria telecom industry revealed that strategic agility influence competitive performance. Cavazotte et al (2013) examine transformational leaders and work performance. The result showed that perceived transformational leadership is associated with higher level of task performance and helping behavior. Grunbaum (2014) examined transformation capability and profitability of small and medium sized enterprises operating in volatile environment and revealed a positive relationship between the variables. Chew and Lo (2008) studied core capabilities and competition strategies of Chinese small and medium-sized enterprises, the result showed that core capabilities are closely related to competition strategy .Akinbade (2014) examined transformation strategies and improved performance of selected Nigerian telecommunication companies. The findings revealed a positive relationship between transformation strategies and performance in the companies. It was recommended operators should adopt transformation strategies. Olajide(2014) examined change management and its effect on employee performance of Nigeria's telecom industry. The study shows a significant effect of change management and employee performance. It was recommended that telecom industries should be proactive to changes.

Scholars on the field of transformational capabilities and employee performance have over the years established a positive relationship between transformational capabilities and employee related outcomes. They have equally emphasized on different facet of transformation capabilities such as technological, logistic, leadership but have not researched on Decision Autonomy in Aluminium Manufacturing Firms in Anambra State as it relates to their Commitment Level. This is therefore the gap this research seeks to fill.

\subsection{Research Design}

\section{Research Methods}

Because this research is geared towards ascertaining the nature of relationship between the dependent and independent variable, the researcher employed the use of a Correlation Research Design

\section{Sampling Frame}

Table 1: Aluminium Firms in Anambra State

\begin{tabular}{|l|l|l|}
\hline S/N & ORGANIZATIONS & LOCATION \\
\hline 1 & Best Aluminium Manufacturing Limited & Onitsha \\
\hline 2 & AloAluminiumNig Ltd & Nkpor \\
\hline 3 & Flight AluminiumNig Ltd & Onitsha \\
\hline 4 & JoecarisAluminium Ltd & Onisha \\
\hline 5 & Lento AluminiumNig Ltd & Awka \\
\hline 6 & Charted AluminiumNig Ltd & Nnewi \\
\hline 7 & JimexAluminium Industries Nig Ltd & Nnewi \\
\hline 8 & Map Aluminium\& Steal Ind Ltd & Nnewi \\
\hline 9 & SimcoAluminiumNig Ltd & Onitsha \\
\hline 10 & Arcmaster Aluminium Products & Onitsha \\
\hline 11 & SkifAluminim Company & Awka \\
\hline 13 & CeemetalAluminiumInd Ltd & Onitsha \\
\hline
\end{tabular}

Sources: Anambra Ministry of Commerce and Field Survey, 2016.

Table 1 above shows a list of 13 Aluminium firms in operating in Anambra State. Three out of the listed companies were selected using simple random sampling technique. The three selected firms are Flight AluminiumNig Ltd,Map Aluminium\& Steal Ind LtdandArcmaster Aluminium Products located in Onitsha, Nnewi and Onitsha respectively 


\subsection{Population of the Study}

Table 2: Population Table

\begin{tabular}{|l|l|l|l|}
\hline S/N & ORGANIZATION & POPULATION & PROPORTION \\
\hline 1 & Flight AluminiumNig Ltd & $\mathbf{6 7}$ & $\mathbf{. 3 4}$ \\
\hline 2 & Map Aluminium\& Steal Ind Ltd & $\mathbf{5 1}$ & $\mathbf{. 2 6}$ \\
\hline 3 & Arcmaster Aluminium Products & $\mathbf{7 9}$ & $\mathbf{. 4}$ \\
\hline & Total & $\mathbf{1 9 7}$ & $\mathbf{1}$ \\
\hline
\end{tabular}

\section{Source: Field Survey, 2016}

Table 2 above gives a detail of the population of the selected firms. Flight has 67 employees; Map has 51 employees while Arcmaster has 79 making a total of 197 and the proportions of the individual firms against the total population are also given. This will be relevant in allocating questionnaire to the selected firms.

\subsection{Sample Size and Sampling Technique}

The sample size used in the study was 132 determined using Taro Yamane formula

Table 3: Questionnaire Distribution Table

\begin{tabular}{|l|l|l|l|l|}
\hline S/N & ORGANIZATION & POPULATION & PROPORTION & No. DISTRIBUTED \\
\hline 1 & Flight AluminiumNig Ltd & $\mathbf{1 3 2}$ & $\mathbf{. 3 4}$ & $\mathbf{4 5}$ \\
\hline 2 & Map Aluminium\& Steal Ind Ltd & $\mathbf{1 3 2}$ & $\mathbf{. 2 6}$ & $\mathbf{3 4}$ \\
\hline 3 & Arcmaster Aluminium Products & $\mathbf{1 3 2}$ & $\mathbf{. 4}$ & $\mathbf{5 3}$ \\
\hline & Total & & $\mathbf{1}$ & $\mathbf{1 3 2}$ \\
\hline
\end{tabular}

\section{Source: Field Survey}

Table 3 above shows the number of copies of questionnaire distributed to each of the focused firm using the proportion earlier calculated in table 2 above

Table 4: Distribution and Response Rate to the questionnaire

\begin{tabular}{|l|l|l|l|l|}
\hline S/N & ORGANIZATION & No. DISTRIBUTED & No RETURNED & No USED \\
\hline 1 & Flight AluminiumNig Ltd & $\mathbf{4 5}$ & $\mathbf{4 3}$ & $\mathbf{4 0}$ \\
\hline 2 & Map Aluminium\& Steal Ind Ltd & $\mathbf{3 4}$ & $\mathbf{3 0}$ & $\mathbf{3 0}$ \\
\hline 3 & Arcmaster Aluminium Products & $\mathbf{5 3}$ & $\mathbf{5 0}$ & $\mathbf{4 7}$ \\
\hline & Total & $\mathbf{1 3 2}$ & $\mathbf{1 2 3}(\mathbf{9 3 \%})$ & $\mathbf{1 1 7}(\mathbf{8 7 \%})$ \\
\hline
\end{tabular}

\section{Source: Field Survey}

Table 6 above shows that a total of 132 copies of questionnaire were distributed to the employees of the focused organizations, out of which 123 were filled and returned. 6 out of the 123 were invalid due to wrong answers by the respondents. The researcher therefore used 117 copies of the questionnaire which represents $87 \%$ of the sample size.

\subsection{Instrument of Data Collection}

A 5 point Likert scaled questionnaire was used in collecting relevant data for the study; it was arranged ranging from Strongly Agree (5), Agree (4), Strongly Disagree (3), Disagree (2) to Undecided (1).

\subsection{Validity of Instrument}

The researcher made use of a combination of Face Validity and Content Validity. Face validity was geared towards language simplification, structure and face appeal of the questionnaire while content validity made sure that the questionnaire offered coverage. Copies of the questionnaire were sent to different validators and the supervisor also made immense contributions to it.

\subsection{Reliability of the Instrument}

The reliability of the questionnaire was arrived at using Cronbach's Alpha using SPSS.

\section{Source SPSS ver. 20}

\begin{tabular}{|l|l|}
\hline Reliability Statistics \\
\hline Cronbach's Alpha & N of Items \\
\hline .942 & $\mathbf{1 0}$ \\
\hline
\end{tabular}

From the result of the reliability, the result was 0.942 which is high; hence, this means that there is a high degree internal consistency. 


\subsection{Method of Data Analysis}

Pearson's Product Moment Correlation Coefficient was used in analyzing the data. This was in a bid to establish the type of relationship that exists between the dependent and independent variables. The level of significance used was $5 \%$ while $95 \%$ confidence interval reliability was adopted.

\section{Data Presentation And Analysis}

4.1 Data Analysis

In line with the hypothesis formulated, data was presented and analyzed using Pearson's Product Moment Correlation Coefficient.

Table 4.1.1: Questionnaire Analysis

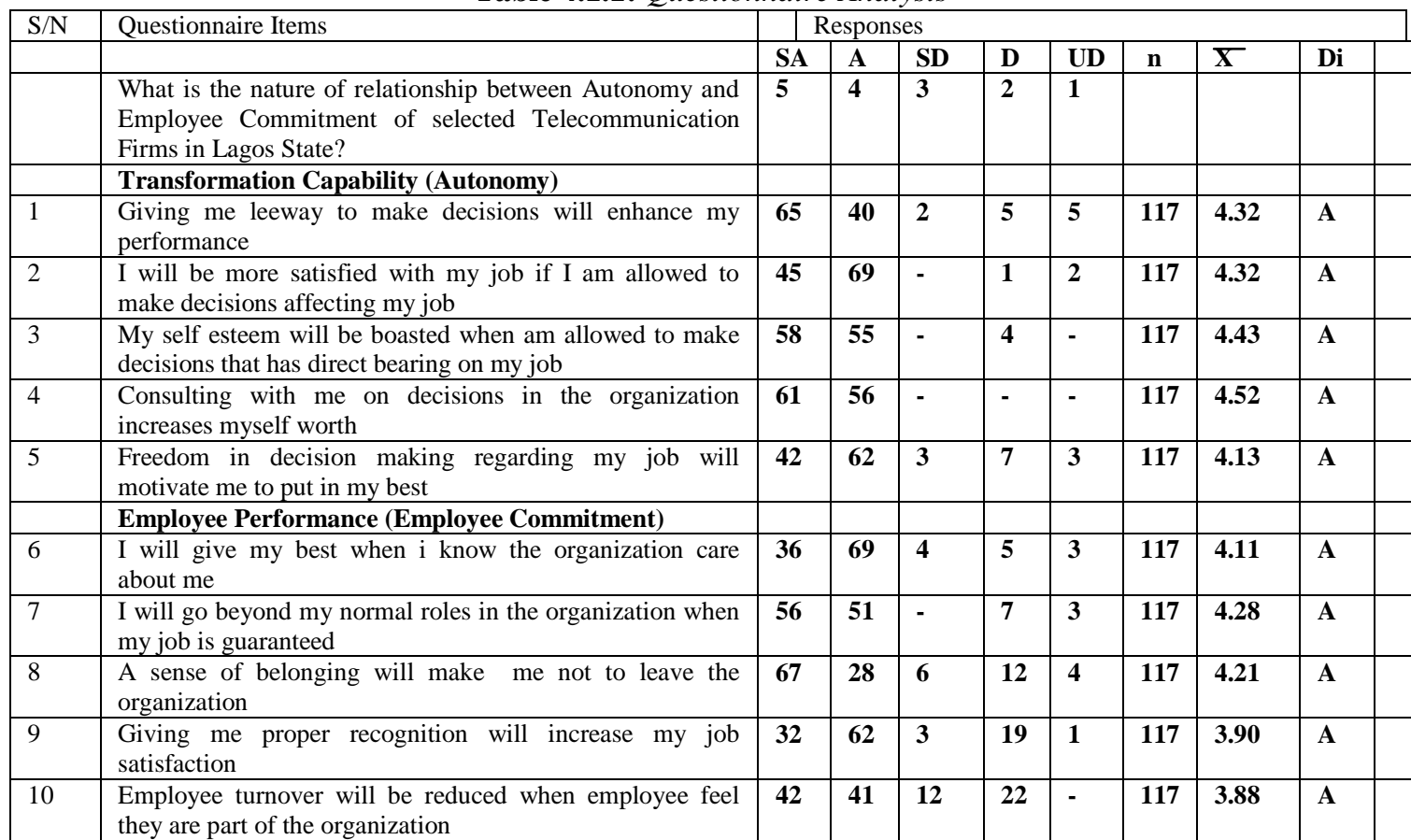

Keys:

$\mathrm{N}=$ Number of respondents

$\bar{X}=$ Mean of responses

$\mathrm{Di}=$ decision

A $=$ Accept

4.2 Test of Hypothesis

Table 4.2: Correlation table

\begin{tabular}{|c|c|c|c|}
\hline \multicolumn{4}{|l|}{ Correlations } \\
\hline & & $\begin{array}{l}\text { DECISION } \\
\text { AUTONOMY }\end{array}$ & $\begin{array}{l}\text { EMPLOYEECO } \\
\text { MMITMENT }\end{array}$ \\
\hline \multirow{3}{*}{$\begin{array}{l}\text { DECISION } \\
\text { AUTONOMY }\end{array}$} & Pearson Correlation & 1 & $.955^{* *}$ \\
\hline & Sig. (2-tailed) & & .000 \\
\hline & $\mathrm{N}$ & 117 & 117 \\
\hline \multirow{3}{*}{$\begin{array}{l}\text { EMPLOYEECOMMI } \\
\text { TMENT }\end{array}$} & Pearson Correlation & $.955^{\text {k* }}$ & 1 \\
\hline & Sig. (2-tailed) & .000 & \\
\hline & $\mathrm{N}$ & 117 & 117 \\
\hline
\end{tabular}

\subsection{Summary of Findings}

\section{Summary Of Findings, Conclusion And Recommendations}

The results obtained from the correlation analysis shows that there is a significant positive type of relationship existing between the two variables with a coefficient of .955 , and looking at the $\mathrm{p}$ value which is .0000 and it is less than 0.01 (at 2-tailed test), we will therefore reject the null hypothesis and accept the alternate hypothesis and state that there is a strong positive type of relationship existing between Decision Autonomy and Employee Commitment. 


\subsection{Discussion of Findings}

From the findings of the analysis carried out, a strong positive type of relationship was seen to be existing between Decision Autonomy and Employee Commitment with a coefficient of .955 . This is in agreement with the findings of Zhangwei, Hangzhou and Xiang (2015) whose study pointed out that innovation culture has remarkably positive effects on transformational performance. Their study further indicated that transformational capabilities evidently mediate the impacts of innovation culture on transformational performance. Also, the findings of Grunbaum and Stenger (2014) corroborated the findings of this study when they concluded that a positive relationship exists between transformation capabilities and innovation performance in the organization they studied.

\subsection{Conclusion}

There is a strong positive relationship between Decision Autonomy and Employee commitment as made evident by the result of the correlation analysis carried out above. The implication of this is that as employees are given more autonomy to make decisions in the organization; their commitment level will also increase.

\subsection{Recommendations}

Sequel to the conclusion above, the researcher makes the following recommendations:

a. Management should empower the employees with autonomy to make decisions as this will have a positive effect on their commitment.

b. The organization should train the employees so that they will be able to make informed decisions when given the power to make decisions.

c. The organization should encourage employees to be part of decision making as it will reduce the amount of money spent on hiring consultants.

\subsection{Contribution to Knowledge}

This work exposes the importance of giving employees autonomy to make decisions regarding their duties in the organization as was made known by the result of the correlation analysis carried out that shows that there is a significant positive relationship between autonomy in decision making and employee commitment. Giving autonomy to employee will increase their self esteem and motivation and this will manifest in their commitment level.

\section{References}

[1]. Ajila, B. \&Awonusi, F (2004) Telecommunication Reform and Effects of Competition on Availability, Quality and Cost of Service in Nigeria. Public policy and administration research, volume 1, number 3, page 18-19

[2]. Akintoya, O.A (2010). A Decade of Mobile Telecommunication in Nigeria- What next?

[3]. Albu, M. (2012). Public Enterprise Reforms in Nigeria, Evidence from the Telecommunication Industry.

[4]. Amit, R. \&Schoemaker, P. (2003) Strategic Assets and Organizational Rent. Strategic management journal, 14(1), 33-46

[5]. Arzika, M. (2000). National Policy on Telecommunications. Retrieved from http:// www.aitinfotech.com/national policy.htm

[6]. Barney, J.B (2012). Firm Resources and Sustained competitive Advantage. Journal of Management 17(1), 99-120

[7]. Biljana, A. \&Dordevic, P (2004) Paradoxical requirements for a theory of organizational change and transformation

[8]. Didia, J.U. (2014) Competitive Awareness and Employee Performance in the Telecommunication Industry of Nigeria.

[9]. Galunic, D.C. (2014) Learning to be Capable; International Journal on Employee Capability. Vol 4, No 2, June 2014

[10]. Gbandi, G. (2012). Telecommunication Reform in Nigeria. The marketing challenges, vol 10, number 2, pp 193-198

[11]. Irefin P, \& Mechanic M. A. (2009). Effects of Employee Commitment on Organizational Performance in Coca Cola Nigeria limited, MaidugiriBorno State. Journal of humanities and social sciences (IOSR-JHSS) volume 19, issue 3, ver. 1

[12]. Lado, T, Boyd, F \& Wright, T. (2012) The Nature and Dynamics of Organizational Capability

[13]. Mayer, J. \& Allen, N. (1997) Commitment in the Workplace. Theory, research and application.

[14]. Miller, D \& Friesen, P.H (1983) Strategy Making and Environment; The third link strategy management journal, 4(3) 221-235

[15]. Ndukwe, E. (2003). The Role of Telecommunication in National Development. Paper presented at $19^{\text {th }}$ Omaloyole Annual Management Lecture. December 5, Victoria Island, Lagos Nigeria.

[16]. Ndukwe, E. (2005). Telecom Liberalization in Nigeria. 'Opening up the market and sector reform' Paper presented at SATCOM

[17]. Nwagharaji, I. (2011). "10 Years of Telecommunication Infrastructure Development in Nigeria" A paper presented at the international conference in innovations and technology,. August $8^{\text {th }}-9^{\text {th }}$.

[18]. Ojo B.U. Intellectual Capital and Organizational Performance. An empirical study in telecomm sector of Nigeria. A paper presented at SATCOM.

[19]. Olajide, O.T. (2014). Change Management and its Effect on Organizational Performance of Telecommunication Industries; Evidence from Airtel Nigeria. International journal of humanities, social sciences and education (IJHSSE) Volume1, Issue 11, PP170-179

[20]. Oyejido, A. (2012). Strategic Agility and Competitive Performance in the Telecoms Industry; An empirical investigation. American international journal of contemporary research. Volume 2, Number 3, March 12

[21]. Teece, D, Pisano, G \&Schuen, A. (2013) Dynamic Capability and Strategic Management. Strategic Management Journal, 18 (7) 509-533

[22]. Zia-ur-Rehman, M \&Taris, S (2012). Employee Commitment and their Performance are Inter-related: A behavioural study from Pakistan. Kuwait chapter of Arabian journal of business. Vol 2, 127-140 